\title{
Similar Clinical Outcomes with Preoperative and Postoperative Start of Thromboprophylaxis in THA: A Register-based Study
}

\author{
Pål O. Borgen MD, Are H. Pripp PhD, Eva Dybvik PhD, \\ Lilian Leistad PhD, Ola E. Dahl MD, PhD, Olav Reikerås MD, PhD
}

Received: 21 December 2016/ Accepted: 9 June 2017/Published online: 22 June 2017

(C) The Association of Bone and Joint Surgeons ( 2017

\begin{abstract}
Background Elective THA is associated with a high risk of thromboembolic events. Although these events may be less common now than they were in the past, they can be serious, and most patients undergoing the procedure therefore still receive thromboprophylaxis. However, controversy remains regarding whether to begin thromboprophylaxis before THA or after to best balance the risks of clotting and bleeding.
\end{abstract}

Each author certifies that neither he, nor any member of his immediate family, have funding or commercial associations (consultancies, stock ownership, equity interest, patent/licensing arrangements, etc) that might pose a conflict of interest in connection with the submitted article.

All ICMJE Conflict of Interest Forms for authors and Clinical Orthopaedics and Related Research ${ }^{\circledR}$ editors and board members are on file with the publication and can be viewed on request.

Each author certifies that his or her institution approved or waived approval for the human protocol for this investigation and that all investigations were conducted in conformity with ethical principles of research.

This work was performed at Martina Hansens Hospital, Gjettum, Norway.

\section{P. O. Borgen $(\bowtie)$}

Department of Orthopaedics, Martina Hansens Hospital,

Dønskiveien 8, 1346 Gjettum, Norway

e-mail: poborgen@gmail.com

\section{A. H. Pripp}

Oslo Centre of Biostatistics and Epidemiology, Research

Support Services, Oslo University Hospital, Oslo, Norway

\section{E. Dybvik}

Norwegian Arthroplasty Register, Department of Orthopaedic

Surgery, Haukeland University Hospital, Bergen, Norway

\section{Leistad}

The Norwegian Patient Register, The Norwegian Directorate of Health, Trondheim, Norway
Questions/purposes We asked the following questions: (1) Is there a difference in bleeding events with pre- versus postoperative thromboprophylaxis? (2) Is there a difference in thromboembolic episodes after THA between the two regimens? (3) How do the two approaches of thromboprophylaxis influence mortality, readmissions, and other complications?

Methods We used a population-based followup design with predefined data based on international health codification to assess clinical effects of LMWH prophylaxis initiated before or after THA. We took data limited to primary THAs done in Norway between January 1, 2008, and December 31, 2011, from the Norwegian Arthroplasty Register and the National Patient Register to have necessary data elements to complete the study. The two registers were merged after identifying patients with their 11-digit personal identification number (Social Security number). We obtained data regarding demographics, administrative and surgical details, and episode histories for prophylaxisrelated events within 180 days of surgery. A total of 25,163 patients undergoing THA were included for analysis, and

\section{O. E. Dahl}

Centre of Medical Science, Education and Innovation, Innlandet Hospital Trust, Elverum, Norway

O. E. Dahl

Thrombosis Research Institute, London, UK

O. Reikerås

Department of Orthopaedics, Oslo University Clinic, Rikshospitalet, Norway 
9977(40\%) versus $15,186(60 \%)$ patients received pre- and postoperative LMWH, respectively. We performed statistical adjustment for differences in baseline characteristics using multivariate logistic regression.

Results After adjustment for age, sex, operation time, year of surgery, and American Society of Anesthesiologists class, we could not show major differences in bleeding events; (odds ratio [OR], 1.04; 95\% CI, 0.88-1.22; p = 0.660), thromboembolic episodes; (OR, 1.03; 95\% CI, $0.84-1.27 ; \mathrm{p}=0.786)$, or other postoperative clinical complications; (OR, 0.86; 95\% CI, 0.76-0.99; p = 0.034), with the two regimens. Six-month mortality was similar, (OR, 0.76; 95\% CI, 0.56-1.05; p = 0.093), and the readmission rate was higher in the preoperative group; (OR, 0.92; 95\% CI, 0.85-0.97; $\mathrm{p}=0.016$ ).

Conclusions The risk for postoperative complications seems to be comparable whether LMWH prophylaxis is initiated before or after THA. The postoperative approach reduces costs, decreases risks related to neuraxial anesthesia, and facilitates same-day admissions. Methods for individual risk assessment including laboratory tests would be feasible.

Level of Evidence Level III, therapeutic study.

\section{Introduction}

THA is associated with perioperative risks including deep venous thrombosis and pulmonary embolism, both of which are manifestations of venous thromboembolism (VTE) [28, 29]. Substantial progress has been made in reducing the risk of VTE after surgery owing to use of thromboprophylactic drugs [9], but also because of better preoperative preparations, refinement in surgical technique, and earlier mobilization $[15,26]$. A trend toward reduced mortality has been observed in recent years despite more patients who are comorbid, and myocardial infarction seems to have replaced pulmonary embolism as the major cause of postoperative deaths [2, 14].

Although a broad consensus for some form of pharmaceutical prophylaxis exists $[9,21]$, the best timing for initial administration remains unclear. In European countries, low-molecular-weight heparin (LMWH) is frequently used during hip replacement surgery, and it has been initiated preoperatively on the assumption that the operation is the main cause of thrombosis [6, 11, 27, 30]. In the United States and Canada, emphasis traditionally has been placed on the risk of bleeding, and postoperative start of thromboprophylaxis has been the standard [16]. Timing, drug, and dose provided are controversial, and divergent definitions of classifications and outcome measures make it difficult to recommend good evidence-based strategies.
It remains unclear whether LMWH should be started before surgery, or held until surgery has been completed. In this study, we therefore used data from two nationwide population-based registers to compare risks associated with preoperative versus postoperative administration of LMWH. We asked the following questions: (1) Is there a difference in bleeding events with pre- versus postoperative thromboprophylaxis? (2) Is there a difference in thromboembolic episodes after THA between the two regimens? (3) How do the two approaches of thromboprophylaxis influence mortality, readmissions, and other complications?

\section{Patients and Methods}

This study has a population-based followup design with data from two national registers. The Norwegian Arthroplasty Register (NAR) receives information on primary and revision joint arthroplasties performed in Norway [12], and registration completeness is high for primary hip arthroplasties [1, 8]. The NAR receives clinical data in a standardized form, identified by the patient's 11-digit personal identification number (Social Security number), and the surgeon completes the form at the time of surgery. The form includes information on age, sex, diagnosis, and operative details. Since 2005, details regarding thromboprophylaxis have been registered. The NAR is linked to Statistics of Norway (https://www.ssb.no/en/) that provides information regarding deaths.

The Norwegian Patient Register (NPR) (http://www.npr.no), established in 1997, is a national health register and contains administrative, medical, and demographic information for all patients waiting for or having received treatment in the specialist health services. The NPR receives information regarding diagnoses using the International Classification of Diseases, 10th Revision (ICD-10), and treatment using the Nordisk medisinalstatistisk kommité (NOMESKO) Classification of Surgical Procedures (NCSP) (http://www.norden.org/en/nordic-councilof-ministers/council-of-ministers/nordic-council-of-ministersfor-health-and-social-affairs-mr-s/institutions-and-co-operativebodies/co-operative-bodies/nordic-medico-statistical-committeenomesko). Reporting to the NPR is mandatory for each hospitalization or outpatient visit and is linked to the reimbursement system. From 2008, data regarding each patient's episode histories have been collected by the NPR and linked to the patient's Social Security number, making tracking of particular individuals possible for research purposes. This determined our selection of the cohorts. The regulations of the NAR and NPR allow linkage of the registries. We included patients undergoing primary THA registered with NCSP codes NFB 20 (uncemented THA), 30 (hybrid THA), and 40 (cemented THA), and reported to the NAR between January 1, 2008, and December 31, 2011. The NPR 
Fig. 1 The flowchart for our study is shown. NPR = Norwegian Patient Register; LMWH = low molecular weight heparin.

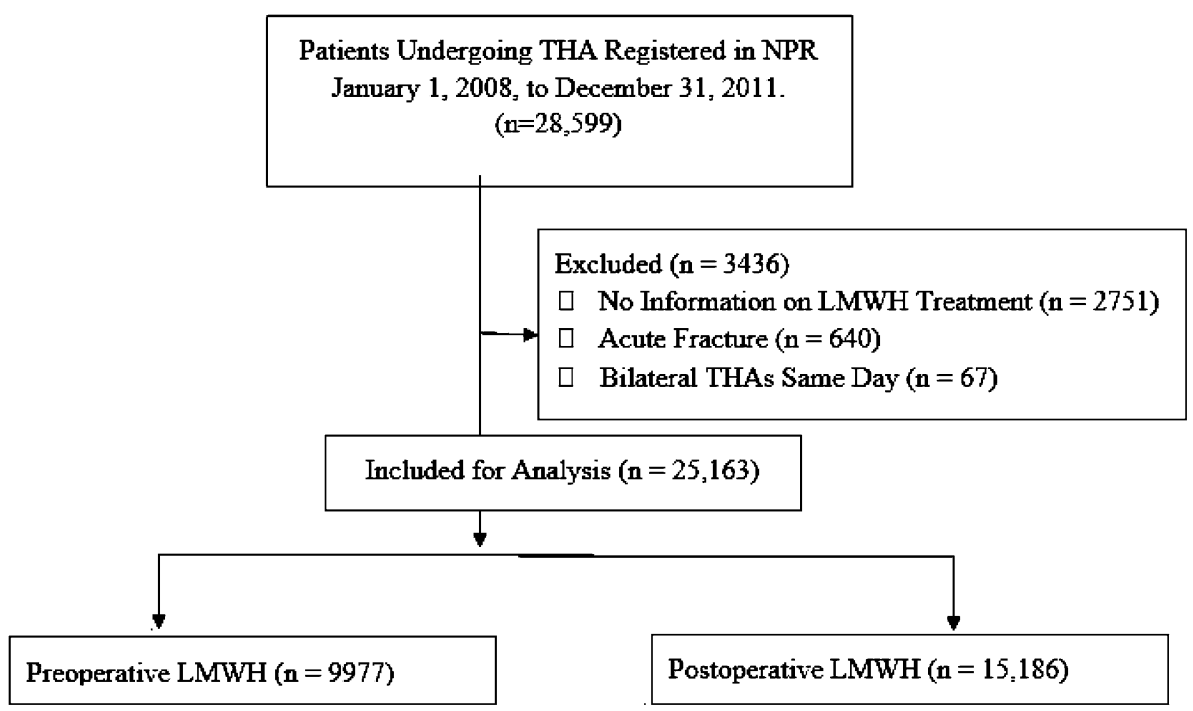

received the Social Security numbers for 28,607 patients undergoing THA from the NAR and 28,599 of these patients also were identified in the NPR (99\% registration completeness). The Social Security numbers were first encrypted, and then replaced by study allocation numbers generated by the NAR, and the two registers were merged to have the necessary data elements to complete the study. The analyzed files did not at any time contain data identifying individual patients. Most symptomatic cases of VTE and readmissions for other complications occur within 3 months after surgery $[3,20]$. We followed the patients for 6 months to be sure that all postoperative complications were registered. To provide information regarding the total disease history of these patients in 6 months after joint arthroplasty, the NPR used the Social Security number to link episodes of treatment registered at all different hospitals from January 1, 2008, to June 30, 2012. This constituted 25,909 patients with registered events, and a total of 67,980 visits available for further analysis. Patients treated for acute fracture (640 patients) were excluded because they present another surgical pathophysiologic challenge. According to NAR, approximately $95 \%$ of patients having primary THA received LMWH as thromboprophylaxis during the period studied, and only $0.1 \%$ of patients received no chemical prophylaxis [31]. We split patients into five groups according to their thromboprophylactic regimen: (1) first dose preoperative $(n=10,322)$; (2) first dose postoperative $(\mathrm{n}=15,534)$; (3) no thromboprophylaxis $(\mathrm{n}=$ 18); (4) no information regarding prophylaxis $(n=220)$; and (5) received prophylaxis but no information regarding timing $(\mathrm{n}=$ 2513). Patients belonging to Groups 3 through 5 were excluded. Patients undergoing a bilateral one-stage procedure also were excluded owing to difficulty identifying procedure-relevant events. Altogether, 25,163 patients were included in the analyses, and $9977(40 \%)$ and $15,186(60 \%)$ patients received pre- versus postoperative LMWH (Fig. 1). This investigation was approved by the regional ethics committee (07.11.2012. Ref. 2012/1580/ REK sør-øst B).

\section{Assessment of Outcomes}

Based on ICD codification, we selected 21 predefined prophylaxis-related events (Table 1). Data recordings of these predefined events were grouped in three categories reflecting possible clinical relevance: (1) bleeding events: anemia, shock, bleeding, hematemesis/melena, and reoperation for bleeding and infection; (2) thromboembolic episodes: pulmonary embolism, phlebitis and thrombophlebitis, other vein thrombosis, posthrombotic syndrome, and arterial embolism/thrombosis; and (3) other clinical complications associated with anticoagulation: angina pectoris, acute myocardial infarction, other acute ischemic heart disease, arrhythmia, disseminated intravascular coagulation, acute respiratory distress syndrome, stroke, fat embolus, and skin infections.

Readmissions and mortality from all causes during the first 180 days after primary THA for the whole population and for the two cohorts also were assessed. Readmission was defined as the first postoperative visit that resulted in hospitalization. Reoperations for dislocation and revision of implants also were recorded.

\section{Statistical Analysis}

Patient characteristics are presented as mean (SD) or number of patients (percentage) as appropriate. Differences in patient baseline characteristics between pre- and 
Table 1. Predefined events among the assessed patients

\begin{tabular}{|c|c|c|c|c|}
\hline Clinical events & ICD-10 and NCSP code & Total event & Preoperative group & Postoperative group \\
\hline \multicolumn{5}{|l|}{ Bleeding events } \\
\hline Anemia & D64 & $189(0.8)$ & $84(0.8)$ & $105(0.7)$ \\
\hline Shock & R57 & $13(0.1)$ & $3(0.0)$ & $10(0.1)$ \\
\hline Bleeding & R58 & $7(0.0)$ & $1(0.0)$ & $6(0.0)$ \\
\hline Hematemesis/melena & K92 & $90(0.4)$ & $39(0.4)$ & $51(0.3)$ \\
\hline Reoperation for bleeding or infection & NFW & 407 (1.6) & $159(1.6)$ & $248(1.6)$ \\
\hline \multicolumn{5}{|l|}{ Thromboembolic events } \\
\hline Pulmonary embolism & I 26 & $124(0.5)$ & $52(0.5)$ & $72(0.5)$ \\
\hline Phlebitis and thrombophlebitis & I 80 & $199(0.8)$ & $75(0.8)$ & $124(0.8)$ \\
\hline Other vein thrombosis & I82 & $101(0.4)$ & $42(0.4)$ & $59(0.4)$ \\
\hline Postthrombotic syndrome & I87 & $21(0.1)$ & $9(0.1)$ & $12(0.1)$ \\
\hline Arterial embolism/thrombosis & I74 & $16(0.1)$ & $8(0.1)$ & $8(0.1)$ \\
\hline \multicolumn{5}{|l|}{ Other clinical complications } \\
\hline Angina pectoris & $\mathrm{I} 20$ & $631(2.5)$ & $309(3.1)$ & $322(2.1)$ \\
\hline Acute myocardial infarction & $\mathrm{I} 21+\mathrm{I} 23.0-9$ & $173(0.7)$ & $78(0.8)$ & $95(0.6)$ \\
\hline Other acute ischemic heart disease & $\mathrm{I} 24$ & $2(0.0)$ & $2(0.0)$ & $0(0.0)$ \\
\hline Stroke & $\mathrm{I} 64+\mathrm{G} 45+\mathrm{G} 46$ & $71(0.3)$ & $21(0.2)$ & $50(0.3)$ \\
\hline Skin infections & L02 & $21(0.1)$ & $9(0.1)$ & $12(0.1)$ \\
\hline Arrhythmia & I49 & $143(0.6)$ & $69(0.7)$ & $74(0.5)$ \\
\hline Disseminated intravascular coagulation & D65 & $33(0.1)$ & $13(0.1)$ & $20(0.1)$ \\
\hline Acute respiratory distress syndrome & $\mathrm{J} 80$ & 0 & 0 & 0 \\
\hline Fat embolus & $\mathrm{T} 79$ & 0 & 0 & 0 \\
\hline Reposition for dislocation & $\mathrm{NFH}$ & 477 (1.9) & $230(2.3)$ & $247(1.6)$ \\
\hline Revision of implants & NFC & $421(1.7)$ & $178(1.8)$ & $243(1.6)$ \\
\hline
\end{tabular}

Number of events (\%); ICD-10 = International Classification of Diseases, Version 2010; NCSP = NOMESKO Classification of Surgical and Medical Procedures.

postoperative groups (Table 2) were assessed with independent samples $t$ test or Pearson's chi-squared test for continuous or categorical variables, respectively. Multivariable logistic regression was used to adjust for possible bias in the comparison of pre- and postoperative groups because of differences in baseline characteristics. In the multivariable model, a defined binary event was the dependent variable (outcome). Independent variables were LMWH group (preoperative start as reference), sex, age (in years), year of operation (treated as a categorical variable), American Society of Anesthesiologists (ASA) classification (treated as a categorical variable) and operation time (in minutes). This approach estimated an odds ratio (OR) of the defined event for pre- and postoperative groups adjusted for sex, age, year of operation, ASA classification, and operation time. The adjusted OR is presented with 95\% CI and probability value. A $\mathrm{p}$ value less than 0.05 was considered statistically significant. Statistical analysis was performed using IBM SPSS Statistics Version 22.0 (IBM Corporation, Armonk, NY, USA). We used Stata SE 14.1 for Windows (StataCorp LLC, College Station, TX, USA) for estimation of statistical power.

\section{Results}

After controlling for age, sex, year of operation, ASA score and operation time, we found no difference between preand postoperative LMWH administration in terms of bleeding events (OR, 1.04; 95\% CI, 0.88-1.22; $\mathrm{p}=0.660$ ) (Table 3). The rate of reoperations for bleeding and infection (NCSP code NFW) were comparable (OR, 1.09; 95\% CI, 0.88-1.34; $\mathrm{p}=0.425$ ). When we analyzed reoperations for bleeding separately, we registered a total of 142 patients equally distributed in the two groups (OR, $1.09 ; 95 \%$ CI, $0.77-1.54 ; \mathrm{p}=0.618$ ). Only 14 of these bleeding events were classified as hematoma. In-depth analyses of possible bleeding events showed equal distribution of open exploration of the hip (five versus four) at 13 to 122 days after surgery (mean, 43 days).

We recorded 407 (1.6\%) patients with thromboembolic episodes, and without differences between the two groups (OR, 1.03; 95\% CI, 0.84-1.27; $\mathrm{p}=0.786$ ). However, there was a lower frequency of patients with events categorized as other complications in the postoperative group (OR, 0.86; 95\% CI, 0.76-0.99; $\mathrm{p}<0.034$ ), and this difference 
Table 2. Patient characteristics

\begin{tabular}{|c|c|c|c|}
\hline Patient characteristic & Total & Preoperative & Postoperative \\
\hline Number of patients & 25,163 & $9977(40)$ & $15,186(60)$ \\
\hline Age - years & & $68.9(10.9)$ & $67.8(11.7)$ \\
\hline \multicolumn{4}{|l|}{ Sex } \\
\hline Female & $16,409(65)$ & $6398(64)$ & $10,011(66)$ \\
\hline Male & $8754(35)$ & $3579(36)$ & $5175(34)$ \\
\hline \multicolumn{4}{|l|}{ Year of operation } \\
\hline 2008 & $6030(24)$ & $3034(30)$ & $2996(20)$ \\
\hline 2009 & $6306(25)$ & $2531(25)$ & $3775(25)$ \\
\hline 2010 & $6496(26)$ & $2280(23)$ & $4216(28)$ \\
\hline 2011 & $6331(25)$ & $2132(21)$ & $4199(28)$ \\
\hline \multicolumn{4}{|l|}{ ASA score } \\
\hline 1 & $5612(22)$ & $2334(23)$ & $3278(22)$ \\
\hline 2 & $14,464(58)$ & $5387(55)$ & $9077(60)$ \\
\hline 3 & 4678 (19) & $2086(21)$ & $2592(17)$ \\
\hline 4 & $74(0.3)$ & $41(0.4)$ & $33(0.2)$ \\
\hline Unknown & $335(1)$ & $129(1)$ & $206(1)$ \\
\hline Operation time (minutes; SD) & & $97.9(31.2)$ & $87.4(29.3)$ \\
\hline Days of thromboprophylaxis (mean, SD) & & $23.7(11.7)$ & $22.1(11.5)$ \\
\hline \multicolumn{4}{|l|}{ Diagnosis (number and \% in group) } \\
\hline Coxarthrosis & 20,095 & $8039(81)$ & $12,056(80)$ \\
\hline Rheumatoid arthritis & 472 & $212(2)$ & $260(2)$ \\
\hline Sequela fracture & 1385 & $661(7)$ & $724(5)$ \\
\hline Sequela dysplasia & 2033 & $609(6)$ & $1424(9)$ \\
\hline Sequela dysplasia (luxation) & 93 & $28(0.3)$ & $65(0.4)$ \\
\hline Sequela Perthes & 29 & $9(0.1)$ & $20(0.1)$ \\
\hline Sequela epiphysiolysis & 12 & $3(0.0)$ & $9(0.1)$ \\
\hline Ankylosing spondylitis & 80 & $39(0.4)$ & $41(0.3)$ \\
\hline
\end{tabular}

Number of patients (\%) in group, mean and SD for continuous variables; ASA score = American Society of Anesthesiologists score.

was more pronounced when we analyzed for diagnoses related to myocardial ischemia (OR, 0.83; 95\% CI, 0.760.99; p < 0.017) (Table 3).

One hundred seventy-five patients $(0.7 \%)$ died, but there was no difference in mortality at 180 days between the two groups (OR, 0.76; 95\% CI, 0.56-1.05; $\mathrm{p}=0.093$ ). However, patients given preoperative medication were more likely to be readmitted to the hospital in that time (OR, 0.92 ; 95\% CI, 0.85-0.97; $\mathrm{p}=0.016$ ).

\section{Discussion}

There is consensus for some form of pharmaceutical prophylaxis owing to the elevated VTE risk in THA $[9,21]$. However, optimal timing of the first dose of thromboprophylactic drugs remains unclear, and owing to lack of head to head studies comparing the same compounds, we sought to determine whether there are differences in bleeding events, thromboembolic episodes, and prophylaxis-related clinical complications with preoperative versus postoperative start of LMWH. We also assessed mortality and readmissions, and we followed the patients for 6 months to be sure that all complications after THA were registered. The data in this study indicate a comparable risk of bleeding events, thromboembolic episodes, other complications, readmissions, and deaths with starting LMWH prophylaxis in patients before or after THA. Thus, there was no evidence of important clinical benefits of either of the regimens.

This study is potentially limited in several ways. The major limitation was that the two study groups were dissimilar at baseline in numerous ways that could bias the comparison. Therefore, comparison was done after statistical adjustment for differences in baseline characteristics using multivariable logistic regression. To the best of our knowledge, we adjusted for important observed confounders, such as sex, age, year of 
Table 3. Adjusted odds ratio of clinical events within 180 days after pre versus postoperative start of LMWH

\begin{tabular}{|c|c|c|c|c|c|c|}
\hline Clinical events & Total $(\%)$ & $\begin{array}{l}\text { Preoperative } \\
\text { LMWH (\%) }\end{array}$ & $\begin{array}{l}\text { Postoperative } \\
\text { LMWH (\%) }\end{array}$ & Adjusted OR & $\mathrm{CI}$ & $\mathrm{p}$ value \\
\hline \multicolumn{7}{|l|}{ Bleeding events: } \\
\hline $\begin{array}{c}\mathrm{D} 64+\mathrm{R} 57+\mathrm{R} 58+ \\
\text { K92 + NFW }\end{array}$ & $686(2.7)$ & $279(2.8)$ & $407(2.7)$ & 1.04 & $0.88-1.22$ & 0.660 \\
\hline \multicolumn{7}{|l|}{$\begin{array}{l}\text { Reoperation for } \\
\text { bleeding/infection: }\end{array}$} \\
\hline NFW & 407 (1.6) & $159(1.6)$ & 248 (1.6) & 1.09 & $0.88-1.34$ & 0.425 \\
\hline \multicolumn{7}{|l|}{$\begin{array}{l}\text { Thromboembolic } \\
\text { episodes: }\end{array}$} \\
\hline $\begin{array}{l}\mathrm{I} 26+\mathrm{I} 80+\mathrm{I} 82+\mathrm{I} 87 \\
\quad+\mathrm{I} 74\end{array}$ & $411(1.6)$ & $165(1.7)$ & $246(1.6)$ & 1.03 & $0.84-1.27$ & 0.786 \\
\hline \multicolumn{7}{|l|}{ Other complications: } \\
\hline $\begin{array}{l}\mathrm{I} 20+\mathrm{I} 21+\mathrm{I} 23+\mathrm{I} 24 \\
\quad+\mathrm{I} 64+\mathrm{G} 45+\mathrm{G} 46 \\
\quad+\mathrm{L} 02+\mathrm{I} 49+\mathrm{D} 65 \\
\quad+\mathrm{J} 80\end{array}$ & $981(3.9)$ & $456(4.6)$ & $525(3.5)$ & 0.86 & $0.76-0.99$ & $<0.034$ \\
\hline \multicolumn{7}{|l|}{ Myocardial ischemia: } \\
\hline $\mathrm{I} 20+\mathrm{I} 21+\mathrm{I} 23+\mathrm{I} 24$ & $731(3.1)$ & $370(3.7)$ & $401(2.6)$ & 0.83 & $0.76-0.99$ & $<0.017$ \\
\hline \multicolumn{7}{|l|}{ Mortality } \\
\hline 30 days & $54(0.21)$ & $30(0.3)$ & $24(0.2)$ & 0.53 & $0.30-0.94$ & $<0.030$ \\
\hline 90 days & $110(0.44)$ & $56(0.6)$ & $54(0.4)$ & 0.74 & $0.50-1.10$ & 0.140 \\
\hline 180 days & $175(0.70)$ & $88(0.9)$ & $87(0.6)$ & 0.76 & $0.56-1.05$ & 0.093 \\
\hline \multicolumn{7}{|l|}{ Readmission } \\
\hline 30 days & $2819(11.2)$ & $1210(12.1)$ & 1609 (10.6) & 1.09 & $1.00-1.18$ & $<0.044$ \\
\hline 90 days & $3779(15.0)$ & $1619(16.2)$ & $2160(14.2)$ & 1.08 & $1.00-1.16$ & $<0.042$ \\
\hline 180 days & $5190(21.6)$ & $2199(22.1)$ & 2989 (19.7) & 0.92 & $0.85-0.97$ & $<0.016$ \\
\hline
\end{tabular}

Preoperative group is reference; number of events $(\%)$ in group; LMWH = low-molecular-weight heparin; OR = odds ratio.

operation, ASA classification, and operation time, which could influence the results using this regression approach. Adjustment of differences in baseline characteristics using multivariable regression models is a common statistical methodology in cohort studies. Data also were assessed with alternative statistical methods, including multivariable Cox regression and Poisson regression, taking into account time at risk, but with no substantial difference in results. Multivariable logistic regression therefore was used in all assessments for ease of presentation. We also performed power analysis to detect differences using the sample size of the current study. There was more than $80 \%$ statistical power to detect $0.5 \%$, $1 \%$, and $1.5 \%$ differences between post- and preoperative groups for events with rates of $2 \%, 10 \%$, and $20 \%$, respectively. Although we performed multivariate analyses, unmeasured and residual confounding remains a general threat to all observational studies. Second, postoperative start of thromboprophylaxis became more common during the study period, which may have influenced balancing of the two cohorts. Therefore, statistical adjustment of relevant confounders was conducted as previously described, but this did not change our results. Third, there are inherent pitfalls of extracting data from national administrative databases. Registration completeness is high for primary THA in the NAR (98\%) [1, 8], and for stroke diagnoses in the NPR (sensitivity, $86.1 \%$; specificity, $99.9 \%$; and positive predictive value, 93.5\%) [33]. Completeness and quality of other risk factors collected in Scandinavian health registers are high because of regular quality controls $[19,23,25]$, but we found no publications regarding the quality of the input to the NPR of other diagnosis and procedure codes. However, there is reason to believe that misclassifications would be independent of the two prophylaxis groups. Furthermore, because the NPR uses the ICD-10 coding standard of diagnoses, deaths in hospitals were defined as having occurred when the patient's last contact was registered at the date of death. Because a large number of patients died outside the institutions reporting to the NPR, analyses of reason for death were excluded. Fourth, we did not have detailed information regarding concomitant medication and comorbidities, which are known confounders in such a study, except ASA classes. Data also were assessed with alternative statistical methods including Cox regression 
and Poisson regression, taking into account time at risk but with no substantial difference in results. Logistic regression therefore was used in all assessments for ease of presentation.

Classification and reporting of bleeding in randomized controlled trials varies widely [7]. In this study, we relied on the ICD-10-coded clinical events reported by all Norwegian hospitals. Estimations of "Major bleeding," a term frequently used in hip arthroplasty trials, have been reported from $0.1 \%$ to $3.1 \%$ [7], and vary even more with other bleeding definitions [4, 5, 13]. Although the criteria to report on this term vary substantially and affect trial results, by using the ICD-10 codification, we found a bleeding rate of $2.7 \%$, which is within this range, and with no difference between the two cohorts. In a case-control study, Parvizi et al. [22] reported an influence of anticoagulation on postoperative hematoma, transfusion requirements, and infection comparing warfarin prophylaxis and controls. We found no differences in hematoma formation or infections between the two approaches of LMWH prophylaxis. One hundred forty-two patients had reoperations caused by bleeding, and these were equally distributed between groups. Even when we analyzed each subgroup for possible bleeding complications, we found very few and a similar number of patients with early postoperative surgical exploration, which could be associated with hematoma formation. We found no differences between the groups.

We found a frequency of symptomatic VTE of $1.6 \%$, symptomatic deep venous thrombosis of $1.3 \%$, and pulmonary embolism of $0.5 \%$ after 180 days, in the pre- and postoperative groups, respectively. These frequencies are similar and in accordance with an earlier study which showed incidences of VTE (symptomatic and nonsymptomatic) within 3 months of THA ranging from $1.4 \%$ to $6 \%$, symptomatic deep venous thrombosis ranging from $0.2 \%$ to $4.4 \%$, and fatal and nonfatal pulmonary embolism ranging from $0.1 \%$ to $0.3 \%$, in patients receiving thromboprophylaxis [25]. Our rate of postthrombotic syndrome was only $0.1 \%$, but comparable to those in another study $(0.2 \%)$ [10], and we believe that only postthrombotic syndrome with pronounced symptoms is reported to the registers. Again, there were no differences between the groups, and the similarities between the groups indicate the same protective benefit against symptomatic VTE with starting LMWH before or after surgery. There were slightly more patients in the preoperative cohort with other complications. When we looked at cardiac-related events separately, this difference was even greater. Myocardial ischemia is a major cause of early postoperative death after THA [17, 18, 24]. Hunt et al. [14] reported that the 90-day death rate for patients having THA in the UK steadily decreased from $0.56 \%$ in 2003 to $0.29 \%$ in 2011 . This could explain why we observed a tendency for more deaths during the first 30 days and more readmissions in the preoperative group during the 6-month followup. The mortality for the total study population was higher than reported by Hunt et al., however, Pedersen al. [25] performed a review of death certificates in Denmark for patients who underwent surgery between 1995 and 2006, and found an overall death rate after 90 days of $1.0 \%$. The quality of reporting on date of deaths in the Scandinavian registers is high, owing to a homogeneous and stable population, which may explain this difference. We have not analyzed data regarding reasons for death, because numerous patients died outside the institutions reporting to the NPR.

Some studies report the predictors of, and complications associated with THA readmissions, usually within 30 days and typically at a rate of approximately 5\% [20, 35]. Weinberg et al. [34] reported a 90-day readmission rate of $6 \%$, and proposed this as a threshold for expected readmission rates after THA. In a Canadian multicenter prospective cohort study including patients having THA, van Walraven et al. [32], found a 180-day readmission rate of $13.5 \%$. They called for preoperative risk stratification not only for VTE. The rate of readmissions in our study was $21 \%$, and highest in the preoperative group even after the statistical adjustment. The preoperative group had more patients in ASA Classes 3 and 4, which may contribute to these findings, although we adjusted for ASA class in the statistical model. This subset of patients with premorbid conditions might possibly need specific protection and attention to minimize and avoid thrombindriven and other postoperative complications. Analyzing rare events after THA using a randomized controlled study design is difficult owing to the large number of patients needed to show differences. A population-based register study, including all patients treated during a specified period, may provide assessment of a causal relationship, although there might be unmeasured confounding or other biases.

We could not show any consistent differences in efficacy and similar safety between pre- and postoperative start of LMWH prophylaxis for patients undergoing THA. Therefore, postoperative start with LMWH appears acceptable for the majority of patients, taking into account the reduced costs, decreased risk of anesthesiology complications, and same-day admissions. Methods to identify patients at high risk and tailoring thromboprophylaxis are needed.

\section{References}

1. Arthursson AJ, Furnes O, Espehaug B, Havelin LI, Soreide JA. Validation of data in the Norwegian Arthroplasty Register and the Norwegian Patient Register: 5,134 primary total hip arthroplasties and revisions operated at a single hospital between 1987 and 2003. Acta Orthop. 2005;76:823-828.

2. Berstock JR, Beswick AD, Lenguerrand E, Whitehouse MR, Blom AW. Mortality after total hip replacement surgery: a systematic review. Bone Joint Res. 2014;3:175-182. 
3. Bjornara BT, Gudmundsen TE, Dahl OE. Frequency and timing of clinical venous thromboembolism after major joint surgery. $J$ Bone Joint Surg Br. 2006;88:386-391.

4. Borgen PO, Dahl OE, Reikeras O. Preoperative versus postoperative initiation of dalteparin thromboprophylaxis in THA. Hip Int. 2010;20:301-307.

5. Borgen PO, Dahl OE, Reikeras O. Blood loss in cemented THA is not reduced with postoperative versus preoperative start of thromboprophylaxis. Clin Orthop Relat Res. 2012;470:2591-2598.

6. Dahl OE, Aspelin T, Lyberg T. The role of bone traumatization in the initiation of proximal deep vein thrombosis during cemented hip replacement surgery in pigs. Blood Coagul Fibrinolysis. 1995;6:709-717.

7. Dahl OE, Quinlan DJ, Bergqvist D, Eikelboom JW. A critical appraisal of bleeding events reported in venous thromboembolism prevention trials of patients undergoing hip and knee arthroplasty. J Thromb Haemost. 2010;8:1966-1975.

8. Espehaug B, Furnes O, Havelin LI, Engesaeter LB, Vollset SE, Kindseth O. Registration completeness in the Norwegian Arthroplasty Register. Acta Orthop. 2006;77:49-56.

9. Falck-Ytter Y, Francis CW, Johanson NA, Curley C, Dahl OE, Schulman S, Ortel TL, Pauker SG, Colwell CW Jr. Prevention of VTE in orthopedic surgery patients: Antithrombotic Therapy and Prevention of Thrombosis, 9th ed: American College of Chest Physicians Evidence-Based Clinical Practice Guidelines. Chest. 2012;141(2 suppl):e278S-e325S.

10. Fitzgerald SJ, McAndrew CM, Kraay MJ, Goldberg VM. Incidence of postthrombotic syndrome in patients undergoing primary total hip arthroplasty for osteoarthritis. Clin Orthop Relat Res. 2011;469:530-534.

11. Gallus AS, Hirsh J, Tutle RJ, Trebilcock R, O’Brien SE, Carroll JJ, Minden JH, Hudecki SM. Small subcutaneous doses of heparin in prevention of venous thrombosis. $N$ Engl $\mathrm{J}$ Med. 1973;288:545-551.

12. Havelin LI, Espehaug B, Vollset SE, Engesaeter LB, Langeland N. The Norwegian arthroplasty register: a survey of 17,444 hip replacements 1987-1990. Acta Orthop Scand. 1993;64:245-251.

13. Hull RD, Pineo GF, Stein PD, Mah AF, MacIsaac SM, Dahl OE, Ghali WA, Butcher MS, Brant RF, Bergqvist D, Hamulyak K, Francis CW, Marder VJ, Raskob GE. Timing of initial administration of low-molecular-weight heparin prophylaxis against deep vein thrombosis in patients following elective hip arthroplasty: a systematic review. Arch Intern Med. 2001;161:1952-1960.

14. Hunt LP, Ben-Shlomo Y, Clark EM, Dieppe P, Judge A, MacGregor AJ, Tobias JH, Vernon K, Blom AW, National Joint Registry for England, Wales and Northern Ireland. 90-day mortality after 409,096 total hip replacements for osteoarthritis, from the National Joint Registry for England and Wales: a retrospective analysis. Lancet. 2013;382:1097-1104.

15. Husted H, Otte KS, Kristensen BB, Orsnes T, Wong C, Kehlet H. Low risk of thromboembolic complications after fast-track hip and knee arthroplasty. Acta Orthop. 2010;81:599-605.

16. Kearon C, Hirsh J. Starting prophylaxis for venous thromboembolism postoperatively. Arch Intern Med. 1995;155:366-372.

17. Lie SA, Engesaeter LB, Havelin LI, Furnes O, Vollset SE. Early postoperative mortality after 67,548 total hip replacements: causes of death and thromboprophylaxis in 68 hospitals in Norway from 1987 to 1999. Acta Orthop Scand. 2002;73:392-399.

18. Lu N, Misra D, Neogi T, Choi HK, Zhang Y. Total joint arthroplasty and the risk of myocardial infarction: a general population, propensity score-matched cohort study. Arthritis Rheumatol. 2015;67:2771-2779.

19. Ludvigsson JF, Andersson E, Ekbom A, Feychting M, Kim JL, Reuterwall C, Heurgren M, Olausson PO. External review and validation of the Swedish national inpatient register. BMC Public Health. 2011;11:450.

20. Mednick RE, Alvi HM, Krishnan V, Lovecchio F, Manning DW. Factors affecting readmission rates following primary total hip arthroplasty. J Bone Joint Surg Am. 2014;96:1201-1209.

21. Mont MA, Jacobs JJ, Boggio LN, Bozic KJ, Della Valle CJ, Goodman SB, Lewis CG, Yates AJ Jr, Watters WC 3rd, Turkelson CM, Wies JL, Donnelly P, Patel N, Sluka P; AAOS. Preventing venous thromboembolic disease in patients undergoing elective hip and knee arthroplasty. J Am Acad Orthop Surg. 2011;19:768-776.

22. Parvizi J, Ghanem E, Joshi A, Sharkey PF, Hozack WJ, Rothman RH. Does "excessive" anticoagulation predispose to periprosthetic infection? J Arthroplasty. 2007;22(6 suppl 2):24-28.

23. Pedersen A, Johnsen S, Overgaard S, Soballe K, Sorensen HT, Lucht U. Registration in the danish hip arthroplasty registry: completeness of total hip arthroplasties and positive predictive value of registered diagnosis and postoperative complications. Acta Orthop Scand. 2004;75:434-441.

24. Pedersen AB, Baron JA, Overgaard S, Johnsen SP. Short- and long-term mortality following primary total hip replacement for osteoarthritis: a Danish nationwide epidemiological study. J Bone Joint Surg Br. 2011;93:172-177.

25. Pedersen AB, Sorensen HT, Mehnert F, Overgaard S, Johnsen SP. Risk factors for venous thromboembolism in patients undergoing total hip replacement and receiving routine thromboprophylaxis. J Bone Joint Surg Am. 2010;92:2156-2164.

26. Salvati EA, Sharrock NE, Westrich G, Potter HG, Valle AG, Sculco TP. The 2007 ABJS Nicolas Andry Award: three decades of clinical, basic, and applied research on thromboembolic disease after THA: rationale and clinical results of a multimodal prophylaxis protocol. Clin Orthop Relat Res. 2007;459:246-254.

27. Sharnoff JG, DeBlasio G. Prevention of fatal postoperative thromboembolism by heparin prophylaxis. Lancet. 1970;2:1006-1007.

28. Sharrock NE, Go G, Harpel PC, Ranawat CS, Sculco TP, Salvati EA. The John Charnley Award: thrombogenesis during total hip arthroplasty. Clin Orthop Relat Res. 1995;319:16-27.

29. Stamatakis JD, Kakkar VV, Sagar S, Lawrence D, Nairn D, Bentley PG. Femoral vein thrombosis and total hip replacement. Br Med J. 1977;2:223-225.

30. Strebel N, Prins M, Agnelli G, Buller HR. Preoperative or postoperative start of prophylaxis for venous thromboembolism with low-molecular-weight heparin in elective hip surgery? Arch Intern Med. 2002;162:1451-1456.

31. The Norwegian Arthroplasty Register. Annual Report 2013. Available at: http://nrlweb.ihelse.net/Rapporter/Rapport2013.pdf. Accessed February 15, 2013.

32. van Walraven C, Jennings A, Taljaard M, Dhalla I, English S, Mulpuru S, Blecker S, Forster AJ. Incidence of potentially avoidable urgent readmissions and their relation to all-cause urgent readmissions. CMAJ. 2011;183:E1067-1072.

33. Varmdal T, Bakken IJ, Janszky I, Wethal T, Ellekjaer H, Rohweder G, Fjaertoft H, Ebbing M, Bonaa KH. Comparison of the validity of stroke diagnoses in a medical quality register and an administrative health register. Scand $J$ Public Health. 2016;44:143-149.

34. Weinberg DS, Kraay MJ, Fitzgerald SJ, Sidagam V, Wera GD. Are readmissions after THA preventable? Clin Orthop Relat Res. 2017;475:1414-1423.

35. Williams J, Kester BS, Bosco JA, Slover JD, Iorio R, Schwarzkopf R. The association between hospital length of stay and 90-day readmission risk within a total joint arthroplasty bundled payment initiative. J Arthroplasty. 2017;32:714-718. 